\title{
Rapid preparation of a patient with pheochromo- cytoma with labetolol and magnesium sulfate
}

\section{[La préparation, avec labétolol et sulfate de magnésium, d'un patient atteint de} phéochromocytome]

Ruban Poopalalingam mbBs mmed, Eugene Yew-Ren Chin MBbS Mmed Fams

Purpose: To describe the rapid perioperative optimization and control of blood pressure in a young patient who presented with pheochromocytoma. He was non-compliant with phenoxybenzamine but insisted on early surgery. He was scheduled for laparoscopic resection of the tumour.

Clinical features: This 32-yr-old man presented with uncontrolled hypertension for a few years for which he was treated with nifedipine. He subsequently defaulted follow-up. The patient presented again approximately three months from the day of surgery and was diagnosed to have a pheochromocytoma. The endocrinologist prescribed phenoxybenzamine and propanolol in addition to the nifedipine but the patient stopped taking both drugs six weeks prior to surgery due to their side effects. The patient was admitted the evening before surgery to the intensive care unit for rapid control of his blood pressure. Blood pressure was optimized with an infusion of labetolol and volume expansion titrated under central venous catheter and intraarterial blood pressure guidance throughout the night. On the morning of surgery, a magnesium sulfate infusion was started. The laparoscopic surgery proceeded uneventfully and the patient was hemodynamically stable. There were two transient periods of hypotension after induction and at removal of tumour respectively which were corrected with a brief adrenaline infusion. No adverse outcome was noted.

Conclusion: This case highlights the possibility of a more rapid perioperative control of pheochromocytoma using high doses of labetolol and a magnesium sulfate infusion to achieve stable intraoperative hemodynamics during laparoscopic resection of pheochromocytoma.

Objectif : Décrire l'optimisation et le contrôle périopératoire rapides de la tension artérielle chez un jeune patient atteint d'un phéochromocytome. Le patient avait cessé de prendre la phénoxybenzamine prescrite, mais insistait pour être opéré rapidement. Une résection laparoscopique de la tumeur a été planifiée.
Éléments cliniques : Un jeune homme de 32 ans souffrait depuis quelques années d'hypertension non contrôlée, traitée avec de la nifédipine, mais il n'a pas respecté le suivi proposé. Puis, il s'est présenté de nouveau, trois mois environ avant la date prévue de l'intervention chirurgicale, et un diagnostic de phéochromocytome a alors été posé. L'endocrinologue a prescrit de la phénoxybenzamine et du propanolol, en plus de la nifédipine, mais le patient a cessé de prendre les deux médicaments six semaines avant l'opération à cause de leurs effets secondaires. La veille de l'opération, il a été hospitalisé aux soins intensifs pour qu'on puisse contrôler rapidement sa tension artérielle. Une perfusion de labétolol et l'expansion volumique titrée au moyen d'un cathéter veineux central ainsi que la surveillance continue pendant la nuit de la tension intra-artérielle ont permis de stabiliser la tension. Le matin de l'opération, une perfusion de sulfate de magnésium a été amorcée. L'intervention laparoscopique s'est déroulée sans incident et dans des conditions de stabilité hémodynamique. II y a eu deux épisodes transitoires d'hypotension après l'induction et au moment de la résection tumorale, mais ils ont été corrigés avec une brève perfusion d'adrénaline. Aucun complication n'a été notée.

Conclusion : Ce cas illustre la possibilité d'un contrôle périopératoire plus rapide d'un phéochromocytome grâce à des doses élevées de labétolol et à une perfusion de sulfate de magnésium utilisées pour stabiliser l'hémodynamie peropératoire.

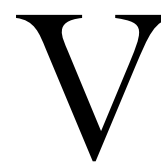

ARIOUS perioperative and anesthetic techniques have been described for the management of a patient who presents with a pheochromocytoma. ${ }^{1,2}$ The management of these patients poses a significant anesthetic challenge particularly in laparoscopic resection of pheochromocytoma. Laparoscopy and pneumoperi-

From the Department of Anaesthesia and Surgical Intensive Care, Singapore General Hospital, Singapore.

Address correspondence to: Dr. P. Ruban, Department of Anaesthesia and Surgical Intensive Care, Singapore General Hospital, Outram Road, Singapore 169608. Phone: 65-3214220; Fax: 65-2241792; E-mail: rumini@singnet.com.sg

Accepted for publication April 2, 2001.

Revision accepted July $9,2001$. 
toneum cause well described hemodynamic disturbances in these patients. ${ }^{3}$ We report a case of laparoscopic resection of pheochromocytoma in a patient who refused preoperative control of blood pressure with phenoxybenzamine and propranolol.

\section{Case report}

A 32-yr-old $54 \mathrm{~kg}$ man with no other past medical history presented with a two-year history of poorly controlled hypertension which was discovered incidentally during a routine pre-employment medical examination. His blood pressure then was $180 / 120$ and he was on nifedipine long acting (LA) $30 \mathrm{mg}$ once in the morning. He, however, defaulted therapy and presented again approximately three months from the date of the surgery. A diagnosis of pheochromocytoma was made based on his 24-hr biochemical urine analysis: the VMA (vanillylmandelic acid) was $81 \mu \mathrm{moL} \cdot$ day $^{-1}$ (normal range $0-34.3 \mu \mathrm{moL} \cdot \mathrm{day}^{-1}$ ), epinephrine was 52 nmoL. day ${ }^{-1}$ (normal range 0-109 nmoL.day ${ }^{-1}$ ), norepinephrine was $6975 \mathrm{nmoL} \cdot$ day $^{-1}$ (normal range 89-473 nmoL.day ${ }^{-1}$ ), dopamine was $2114 \mathrm{nmoL} \cdot$ day $^{-1}$ (normal range 424-2612 nmoL.day ${ }^{-1}$ ), metanephrine was 534 nmoL. day ${ }^{-1}$ (normal range 400-1600 nmoL $\cdot$ day $^{-1}$ ), normetanephrine was $19206 \mathrm{nmoL} \cdot \mathrm{day}^{-1}$ (normal range $\left.600-1900 \mathrm{nmoL} \cdot \mathrm{day}^{-1}\right)$. An ultrasound of the kidneys and a computed tomography scan of the abdomen revealed a $5.5 \mathrm{~cm} \times 3.8 \mathrm{~cm}$ right adrenal tumour consistent with pheochromocytoma.

The endocrinologist continued the patient on nifedipine LA $30 \mathrm{mg}$ once in the morning and added phenoxybenzamine $10 \mathrm{mg}$ three times a day. At the next follow-up two weeks later, propanolol $10 \mathrm{mg}$ three times a day was added to the therapy. However, after a further two weeks (four weeks after starting phenoxybenzamine), the patient stopped taking the phenoxybenzamine and propanolol and defaulted follow-up. The patient claimed that both drugs made him feel "lousy" and that he feared that phenoxybenzamine may be carcinogenic.

The patient finally returned six weeks later, still refusing to take phenoxybenzamine but insisting on early surgical removal of the tumour. The patient was admitted and brought into the surgical intensive care the evening before surgery. His preoperative investigation (full blood count, urea and electrolytes, electrocardiogram and chest $x$-ray) was essentially normal with a hematocrit of $44.6 \%$. His blood pressure was $180 / 100$ with a heart rate of 65 beats $\cdot \mathrm{min}^{-1}$. There were no significant postural changes. There was no assessment of left ventricular function or cardiac output because he was young, asymptomatic and had no other past medical history. We planned to monitor the

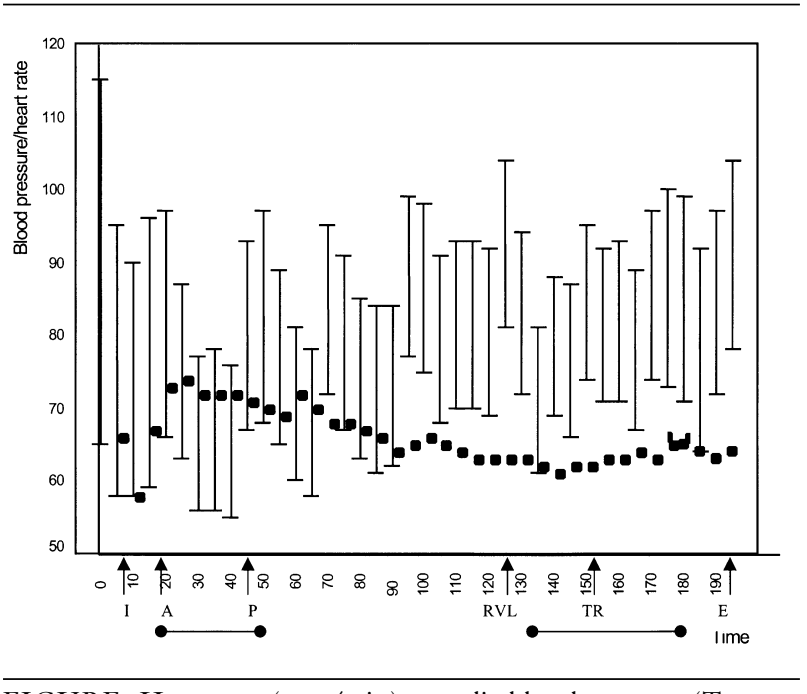

FIGURE Heart rate $(\bullet-/ \mathrm{min})$, systolic blood pressure ( $\mathrm{T}$ $\mathrm{mmHg}$ ) and diastolic blood pressure $(\perp-\mathrm{mmHg}),(\mathrm{I})$ induction of anesthesia, (A) atropine $0.6 \mathrm{mg}$, (P) pneumoperitoneum, (RVL) renal vein ligation, (TR) tumor removal, $(\mathrm{E})$ emergence, $(\bullet \bullet \bullet)$ adrenaline infusion.

patient's blood pressure continuously as we attempted to control the blood pressure with boluses of labetolol. A 20G right radial arterial cannula was inserted and a 7F triple lumen central venous line was sited in the right internal jugular vein under sedation and local anesthetic infiltration. The initial central venous pressure was $11 \mathrm{~cm} \mathrm{H}_{2} \mathrm{O}$.

Throughout the night, boluses of 15 to $50 \mathrm{mg}$ labetolol were titrated, amounting to a total of $550 \mathrm{mg}$ over a 16-hr period preoperatively. The target of preoperative optimization was to maintain the systolic blood pressure at $100-120 \mathrm{mmHg}$, to control heart rate, arrhythmias and to allow restoration of blood volume. Volume expansion was achieved with gelofusine ${ }^{\circledR}$ (iv plasma substitute: succinylated gelatin $40.0 \mathrm{~g}$ molecular weight 30000 , sodium chloride $7.01 \mathrm{~g}$, sodium hydroxide $1.36 \mathrm{~g} ; \mathrm{Na}^{+} 154 \mathrm{mmoL} \cdot \mathrm{L}^{-1}, \mathrm{Cl}^{-} 120$ $\mathrm{mmoL} \cdot \mathrm{L}^{-1}$, pH 7.1-7.7, osmolarity $274 \mathrm{mosm} \cdot \mathrm{L}^{-1}$ ) while maintaining a central venous pressure $10-13 \mathrm{~cm}$ $\mathrm{H}_{2} \mathrm{O}$. A positive fluid balance of $1400 \mathrm{~mL}$ was achieved during that period. At 07:00 on the morning of surgery, a bolus of magnesium sulfate $2 \mathrm{~g}$ was given and an infusion of $1 \mathrm{~g} \cdot \mathrm{hr}^{-1}$ was started. The patient arrived at the operating theatre at $08: 15$ with a blood pressure of $120 / 70$, a heart rate of 70 beats $\cdot \mathrm{min}^{-1}$ and a central venous pressure of $13 \mathrm{~cm} \mathrm{H}_{2} \mathrm{O}$. After the standard monitors were applied, anesthesia was induced with fentanyl $200 \mu \mathrm{g}$, propofol $100 \mathrm{mg}$ and maintained with end tidal sevoflurane $1.8 \%$ in $66 \%$ nitrous oxide and 
$34 \%$ oxygen. Cisatracurium $10 \mathrm{mg}$ was administered to provide muscle relaxation and facilitate tracheal intubation, artificial ventilation and surgery. The patient was ventilated with a $8-10 \mathrm{~mL} \cdot \mathrm{kg}^{-1}$ tidal volume to maintain an $\mathrm{ETCO}_{2}$ between $30-36 \mathrm{mmHg}$. The patient was positioned in the left lateral decubitus and a fourport technique for laparoscopy was used.

Following induction and intubation, the blood pressure and heart rate fell transiently to $76 \mathrm{mmHg}$ systolic pressure and 37 beats. $\mathrm{min}^{-1}$ respectively requiring atropine $0.6 \mathrm{mg}$ and an infusion of adrenaline 0.12 $\mu \mathrm{g} \cdot \mathrm{kg}^{-1} \cdot \mathrm{min}^{-1}$ for ten minutes. Magnesium sulfate infusion was reduced and maintained at $0.5 \mathrm{~g} \cdot \mathrm{hr}^{-1}$. Throughout the surgery, no other drugs were required to control the blood pressure particularly during patient positioning, skin incision, establishment of pneumoperitoneum or manipulation of the tumour. A total of 1.5 litres of crystalloid was administered intraoperatively during the three-hour surgery with an estimated blood loss of $500 \mathrm{~mL}$ and a urine output of $700 \mathrm{~mL}$. Following ligation of the adrenal vein, the magnesium sulfate infusion was stopped and an adrenaline infusion of $0.12 \mu \mathrm{g} \cdot \mathrm{kg}^{-1} \cdot \mathrm{min}^{-1}$ started to maintain the blood pressure at $95-105$ systolic. The adrenaline infusion was weaned over a period of $45 \mathrm{~min}$ and stopped before extubation. There were no episodes of arrhythmia during the entire procedure. The patient was sent to the surgical intensive care for overnight monitoring. His postoperative blood pressure and heart rate remained stable at $120-130 / 60-70 \mathrm{mmHg}$ and $60-65$ beats. $\mathrm{min}^{-1}$ respectively. There was no significant postoperative somnolence. He has since made an uneventful recovery.

\section{Discussion}

The problems surrounding the perioperative management of pheochromocytoma have been well described. ${ }^{4}$ The main objective in the preoperative optimization of these patients is to control the blood pressure, heart rate, arrhythmias and to allow restoration of blood volume. ${ }^{1}$ There is no consensus on the best pharmacological agent or optimal duration of therapy for the preparation of these patients for pheochromocytoma surgery.

Traditionally, phenoxybenzamine, an $\alpha$-adrenergic antagonist, has been the mainstay of perioperative preparation of these patients, as is the practice in our institution., ${ }^{4,5}$ Phenoxybenzamine has been utilized despite its non-selective $\alpha_{1}$ and $\alpha_{2}$ antagonism, for its non-competitive irreversible blockade. This allows control of blood pressure preoperatively, intraoperatively and particularly during surgical manipulation while allowing volume expansion in these patients. However, the use of phenoxybenzamine is associated with some unwanted side effects that result, particularly, from prolonged blockade resulting, in turn, in postoperative hypotension and somnolence. Furthermore, its action on $\alpha_{2}$ adrenoreceptors may uninhibit the noradrenaline release resulting in undesirable chronotropic and inotropic effects. In the preoperative phase, phenoxybenzamine can cause side effects such as stuffy nose, postural hypotension or somnolence, which might be the reason this patient refused the medication. The duration of preoperative phenoxybenzamine therapy is still the object of much debate, ranging from five ${ }^{5}$ to 14 days. ${ }^{4}$ Frequently, in the preoperative preparation of patients with phenoxybenzamine, a beta-adrenergic blocker is added, after $\alpha$ blockade has been established to assist in the control of blood pressure and to reduce the tachycardia associated with $\alpha$ adrenergic blockade. Also, the $\beta$-adrenoreceptor antagonist would block the cardiac sympathetic drive associated with presynaptic $\alpha_{2}$ adrenoreceptor blockade and reduce the tachycardia and arrhythmias associated with increased concentrations of circulating adrenaline.

Our patient refused to take both phenoxybenzamine and propanolol, as prescribed by the endocrinologist, because of their side effects and the potential "carcinogenic effect" of phenoxybenzamine described on the Internet. Based on the $9^{\text {th }}$ Report on Carcinogens from the U.S. Department of Health and Human Services, Public Health Service, National Toxicology Program, phenoxybenzamine is reasonably anticipated to be a human carcinogen based on sufficient evidence of carcinogenicity in experimental animals. It has induced peritoneal sarcomas and lung tumours when injected $i p$ in mice and rats. There have been no reports of carcinoma in humans due to administration of phenoxybenzamine since the drug was introduced in 1956.

Hence, the patient was taking only his initial medication, nifepidine LA $30 \mathrm{mg}$ once in the morning, preoperatively. This did not provide adequate control of his hemodynamic status for surgical resection of the pheochromocytoma. The patient was insistent on immediate surgery in spite of the perioperative risks. The surgeon agreed to perform the surgery in view of the patient's history of non-compliance with medication and follow-up, on the condition that the patient's condition could be optimized adequately prior to operation.

Labetolol was used in our patient to control blood pressure and heart rate because it was readily available as an $i v$ preparation in our hospital and it provided both $\alpha$ and $\beta$ adrenergic blockade with a relatively short half-life of four hours. Labetolol combines a selective, competitive $\alpha_{1}$ adrenergic blockade and a 
nonselective, competitive $\beta$ adrenergic blockade in a 1:7 ratio following iv administration. This would therefore provide sufficient $\alpha$ and $\beta$ blockade for the duration of surgery but minimize the postoperative hypotension and somnolence associated with the lingering effect of $\alpha$ blockade. Furthermore, its availability in iv form allows it to be used for rapid acute preoperative control of blood pressure. Labetolol was titrated to achieve a systolic blood pressure of 120 $\mathrm{mmHg}$ and a heart rate of $60-70$ beats $\mathrm{min}^{-1}$. Simultaneously, the patient's circulating blood volume was expanded with a colloid, gelofusine ${ }^{\circledR}$, to overcome the problem of volume contraction associated with a norepinephrine secreting pheochromocytoma while maintaining an adequate urine output of $1-2$ $\mathrm{mL} \cdot \mathrm{kg}^{-1} \cdot \mathrm{hr}^{-1}$ and a central venous pressure $10-13 \mathrm{~cm}$ $\mathrm{H}_{2} \mathrm{O}$. The patient achieved a net positive fluid balance of $1400 \mathrm{~mL}$ over $16 \mathrm{hr}$ in the intensive care setting.

Magnesium sulfate was started on the morning of surgery for its antiarrhythmic properties and to provide further hemodynamic stability intraoperatively. Magnesium sulfate has been advocated because it inhibits the release of catecholamines from the adrenal medulla and adrenergic nerve endings, has direct vasodilatory effects and antiarrhythmic properties. ${ }^{6,7}$ This patient was given a loading dose of $2 \mathrm{~g}$ on the morning of surgery and started on an infusion of $1 \mathrm{~g} \cdot \mathrm{hr}^{-1}$, which was subsequently reduced on induction to $0.5 \mathrm{~g} \cdot \mathrm{hr}^{-1}$ and stopped intraoperatively after tumour removal.

There are a multitude of pharmacological agents that have been used for the perioperative management of pheochromocytoma. Prazocin is a selective, competitive $\alpha_{1}$ adrenergic receptor blocker. It would spare the $\alpha_{2}$ receptor and therefore, minimize the $\beta$ adrenergic stimulation of the heart. However, prazocin is a competitive antagonist with a high clearance and short elimination half-life, which may make it ineffective in preventing catecholamine surges during surgery, especially if the morning dose is omitted. Prazocin also has a profound first dose hypotensive effect, which is concentration dependent.

Doxazocin is a competitive and selective $\alpha_{1}$ adrenoreceptor antagonist It can be used as a single agent especially in noradrenaline secreting tumours as it does not block presynaptic $\alpha_{2}$ adrenoreceptors. $\beta$ adrenergic antagonist may be unnecessary unless the tumour secretes adrenaline. Nevertheless, there is still a need for intraoperative $\alpha$ and $\beta$ receptor blockade. ${ }^{1}$

Calcium channel blockers have also been used for perioperative management of pheochromocytoma. Nicardipine has been used to provide reasonable control of arterial vasoconstriction during surgery without prolonged hypotension after tumour removal.
Nicardipine avoids $\alpha$ and $\beta$ receptor block and does not markedly affect blood pressure regulation. ${ }^{8}$

ACE inhibitors or angiotensin II antagonists have been used successfully in patients with pheochromocytoma presenting with congestive cardiac failure or cardiomyopathy.

$\alpha$-methyl-p-tyrosine (AMPT) inhibits the rate limiting step of converting tyrosine to dopa in the synthesis of catecholamines. It can reduce the synthesis of catecholamines by $40-80 \%$ but is associated with undesirable side effects such as crystaluria, extrapyramidal and psychic disturbances. It is useful in inoperable or malignant tumours or those resistant to $\alpha$ blockade.

The blood pressure and heart rate were remarkably stable throughout surgery. There was a brief period of hypotension and bradycardia after induction and intubation that was corrected with atropine and a brief infusion of adrenaline. There was, surprisingly, no adrenergic response to the pneumoperitoneum insufflation, tumour manipulation and resection. Catecholamine release triggered by the creation of pneumoperitoneum has been reported before. ${ }^{3,9,10}$ Immediately after ligation of the adrenal vein, hypotension recurred which was, again, corrected with an adrenaline infusion. It was possible to taper the adrenaline infusion rapidly, prior to extubation because the effects of labetolol would be wearing off at that time. Retrospectively, the two episodes of hypotension could have been minimized, perhaps, with a lower rate of infusion of magnesium.

This case highlights the possibility of a more rapid perioperative control of pheochromocytoma using high doses of labetolol and a magnesium infusion to achieve a stable intraoperative hemodynamic state during laparoscopic resection of pheochromocytoma. The traditional view of a long preoperative stabilization phase with phenoxybenzamine has stood the test of time. However, it appears that it is possible to prepare a patient successfully for laparoscopic resection of pheochromocytoma within $24 \mathrm{hr}$ as illustrated by this case report. While a more prolonged preparation with alpha and beta blockade remains the standard of care, the management of this case may provide insight into the management of a patient presenting for urgent operation when phenoxybenzamine administration is not possible.

\section{References}

1 Prys-Roberts C. Phaeochromocytoma-recent progress in its management. Br J Anaesth 2000; 85: 44-57.

2 Singh G, Kam P. An Overview of anaesthetic issues in phaeochromocytoma. Ann Acad Med Singapore 1998; 27: $843-8$ 
3 Pretorious M, Rasmussen GE, Holcomb GW. Hemodynamic and catecholamine responses to a laparoscopic adrenalectomy for pheochromocytoma in a pediatric patient. Anesth Analg 1998; 87: 1268-70.

4 Hull CJ. Phaeochromocytoma. Diagnosis, preoperative preparation and anaesthetic management. Br J Anaesth 1986; 58: 1453-68.

5 Russell WJ, Metcalfe IR, Tonkin AL, Frewin DB. The preoperative management of phaeochromocytoma. Anaesth Intensive Care 1998; 26: 196-200.

6 James MFM. Use of magnesium sulphate in the anaesthetic management of phaeochromocytoma: a review of 17 anaesthetics. Br J Anaesth 1989; 62: 616-23.

7 Pivalizza EG. Magnesium sulphate and epidural anesthesia in pheochromocytoma and severe coronary artery disease. Anesth Analg 1995; 81: 414-6.

8 Colson P, Ryckwaert F, Ribstein J, Mann C, Dareau S. Haemodynamic heterogeneity and treatment with calcium channel blocker nicardipine during phaeochromocytoma surgery. Acta Anaesthesiol Scand 1998; 42 1114-9.

9 Tauzin-Fin P, Hilbert G, Krol-Houdek M, Gosse P, Maurette $P$. Mydriasis and acute pulmonary oedema complicating laparoscopic removal of phaeochromocytoma. Anaesth Intensive Care 1999; 27: 646-9.

10 Sprung J, O'Hara JF Jr, Gill IS, Abdelmalak B, Sarnaik $A$, Bravo EL. Anesthetic aspects of laparoscopic and open adrenalectomy for pheochromocytoma. Urology 2000; 55: 339-43.

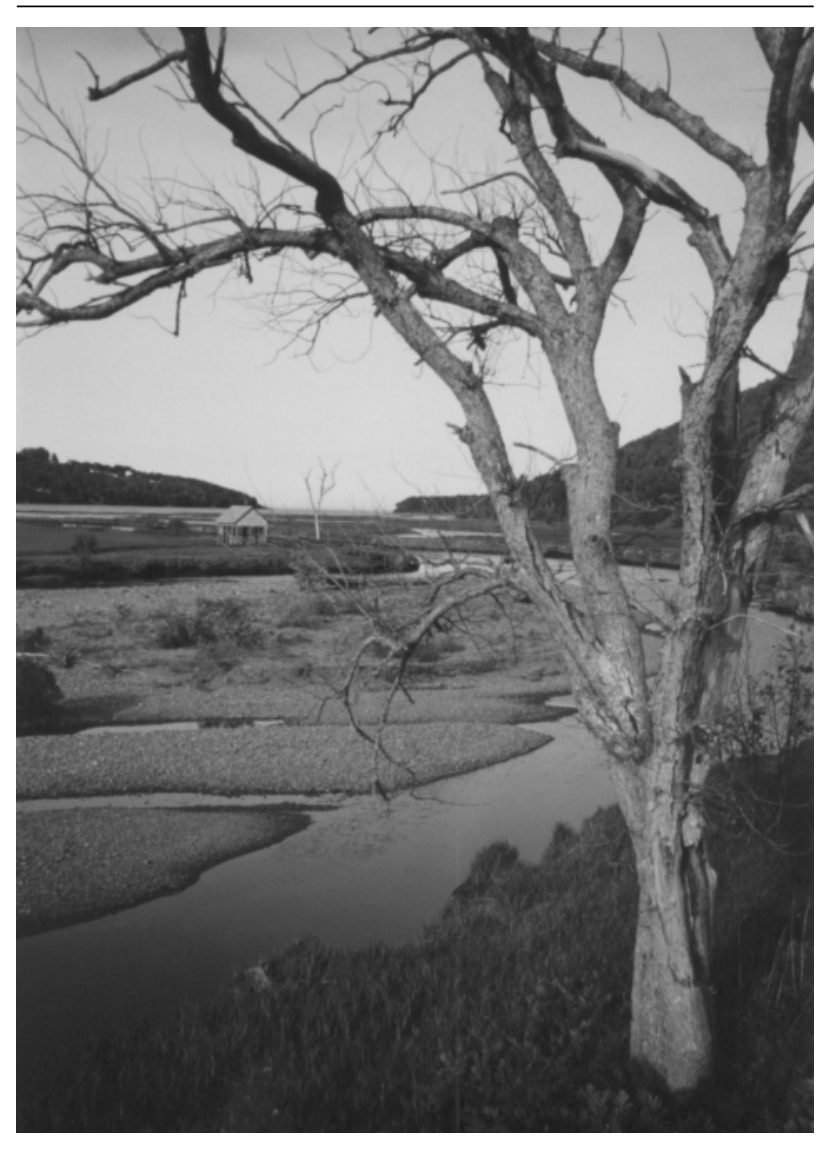

Ingonish - Nova Scotia 